\title{
Verzeichnis der Absendeorte
}

unter Angabe der Briefnummer

Algier 86, 102

Altdorf 11

Arnstadt 72

Arzberg 64

Berlin 29, 38, 92, 181, 211

Biserta 115

Braunschweig 164, 170

Breslau 63, 69, 97, 105, 190

Brieg 90, 104, 114, 123, 139, 140, 151, $175,180,195,202,208,220,221$, 231

Danzig 3, 9, 21, 23, 31, 36, 67, 68, 75, 95, 99, 101, 109, 113, 116, 120,133, 136, 141, 146, 147, 159, 160, 168, $171,173,177,178,198,205,210$, 223, 227, 228, 229, 234

Dedeleben 143, 157, 201, 212, 217

Dresden 2, 44, 49, 53, 78, 82, 87, 174, 191, 225

Eichenbarleben 226

Erfurt 148, 165, 219

Frankfurt am Main 37, 85

Frohndorf 13

Genf 66

Görlitz 71

Göttingen 128, 185

Halberstadt 155, 169, 176, 203, 213 , 236

Halle 5, 6, 19, 41, 42, 43, 45, 46, 47, 56, $57,65,74$

Hamburg 1, 18, 50, 110, 206, 207, 235

Helmstedt 28, 121, 122, 126, 135, 144, $145,152,188,196,216,241$

Hermannstadt 118, 153
Herrendorf 149, 182, 230

Herzberg am Harz 243

Hildesheim 94, 132, 163, 189

Hirschberg 129, 150

Jena 7, 25, 26, 98, 184, 204, 232

Karlsbad 30

Kassel 77

Klein-Kniegnitz 51, 59, 73, 127, 224, 233, 244

Kloster Michaelstein 17

Königsberg 24, 83, 91, 125, 166

Köthen 88

La Calle 111

Laggarben 158

Leipzig 33, 35, 40, 55, 60, 79, 81, 134, 172, 192, 193, 199, 200, 240

London 48

Lübeck 10, 27, 70, 89, 107

Maltzow 179

Markt Herrnsheim 238

Marseille 76

Memmingen 218

Merseburg 8, 15, 245, 246

Michaelstein, s. Kloster Michaelstein

Nürnberg 39

Offenbach 16, 124

Paris 14, 34, 54, 137

Pfuhl 103

Rauten 12, 32

Schleiz 197

Schweidnitz 112, 131, 154, 186

Soldin 215

Stargard in Pommern 209

St. Petersburg 96, 108

Straßburg 62 
Striegau 100

Torgau 183

Tunis 117

Uelzen 4, 20

Weimar 22, 130
Weißenfels 106, 142, 161, 167, 187, 239

Wittenberg 84, 93, 119, 138, 162, 214 , 222, 237

Wolfenbüttel 52, 58, 61, 194, 242

Zürich 80, 156 